\title{
A shallow volatile layer at Chryse Planitia, Mars
}

\author{
Hirohide Demura and Kei Kurita \\ Department of Earth and Planetary Physics, University of Tokyo, 7-3-1 Hongou, Bunkyo, Tokyo 113-0033, Japan
}

(Received August 3, 1997; Revised January 26, 1998; Accepted April 16, 1998)

\begin{abstract}
We have investigated size distribution of rampart craters in the east edge of Chryse Planitia on Mars by Viking high resolution images. Clear existence of the onset diameter of rampart crater, which defines the minimum size of the rampart crater, has been recognized. If this diameter corresponds to the depth to the top of the volatile layer, the converted depth ranges from $\sim 20 \mathrm{~m}$ to $60 \mathrm{~m}$. These values are systematically shallower than the previous estimates (Kuzmin, 1988). Martian volatile layer is thought as a main reservoir of the ancient fluvial processes and atmospheric water vapor. This shallow volatile layer gives us information of the inventory of Martian water and conditions of cryosphere.
\end{abstract}

\section{Introduction}

Present Mars has freezedrying environments at the surface. This climate doesn't permit existence of liquid water and we cannot find out any running water but Martian surface was water-rich in the past according to many geomorphological features; the valley-networks in the ancient heavy cratered terrain, the chaotic terrain for a breakout of water, the mitigating features for creep, and various types of water erosions (e.g., Carr, 1996). Old Martian hydrosphere was different from the present one. It was wet and probably warm. There has been no consensus about the place where the running water had gone after the heavy bombardment stage. Three possibilities have been proposed; 1 . The water has been taken away into the Martian interior; mantle or core under the crust. 2. The water has escaped to space. 3. The water has been caught in the regolith at the surface (e.g., Sleep, 1994).

The first one is excluded because investigation of Martian meteorites indicates water-depleted mantle (McSween, 1994).

The second one is also excluded because significant mechanisms are insufficient to make volatiles escape to space after the heavy bombardment. Although a massive loss of volatiles to space would have occurred on early Mars, it has continued at a much slower rate over the history of the planet (Jakosky and Jones, 1997). Because the thermal escapes, the hydrodynamic escape and Jeans escape, and the impact erosion are only limited in the earliest stage, they don't contribute to the escape after the heavy bombardment. Although the other non-thermal escapes, ion sputtering, etc., have been effective, their total amount is much smaller than that of the surface water estimated by geologic information.

Many researchers consider that the third one is the most appropriate reservoir. The distributions and conditions of volatile layer have been investigated because subsurface volatiles has large influence on the Martian surface envi-

Copy right (c) The Society of Geomagnetism and Earth, Planetary and Space Sciences (SGEPSS); The Seismological Society of Japan; The Volcanological Society of Japan; The Geodetic Society of Japan; The Japanese Society for Planetary Sciences. ronments and evolution of climates. According to a representative model of Clifford (1993) surface of Mars is divided into three layers; the outermost icy layer (permafrost layer), water-depleted cryosphere, and Earth-like ground-water system. But we don't have any direct evidences of such layered structure.

We should explore further evidence of water storage in the regolith layer in the surface morphology. Among indirect evidence of volatile layer, the rampart crater peculiar to Mars is the best candidate of indicator of volatile layer globally mappable on the entire Mars. The rampart crater is a kind of ejecta fluidized crater. It is considered that the ejecta fluidization is made by entraining of volatiles (Carr et al., 1977; Mouginis-Mark, 1981). If excavated material is free from volatiles then lunar-type ordinary craters are formed. Existence of rampart crater indicates the existence of certain amount of volatiles in the excavated material.

It has been said that Martian rampart craters appear to have the lower limit of diameter such as several km sizes (e.g., Boyce, 1980). The diameter is called as the onset diameter of rampart crater.

Kuzmin (1988) mapped variation of the onset diameter of rampart crater on whole Martian surface. The diameter ranges from $2 \mathrm{~km}$ to $6 \mathrm{~km}$. He estimates the depth to the top of the Martian volatile layer ranging from $100 \mathrm{~m}$ to $400 \mathrm{~m}$ based on the distribution of the onset diameter. He states about latitudinal dependence of the depths; the equator-ward zone is deep and pole-ward area is shallow. Although this tendency supports a representative estimation about stability of subsurface volatiles (Fanale et al., 1986), the location is too deep to bring forth the fluvial processes at the surface. It is expected that Clifford's permafrost layer should be checked in high resolution images. Those high resolution images have not been used so far for crater statistics because of the huge quantity of data, partial coverage on Mars, and difficulty of handling the images. This study is an attempt to detect the shallower volatile layer, which would take a main role of fluvial processes at surface. 


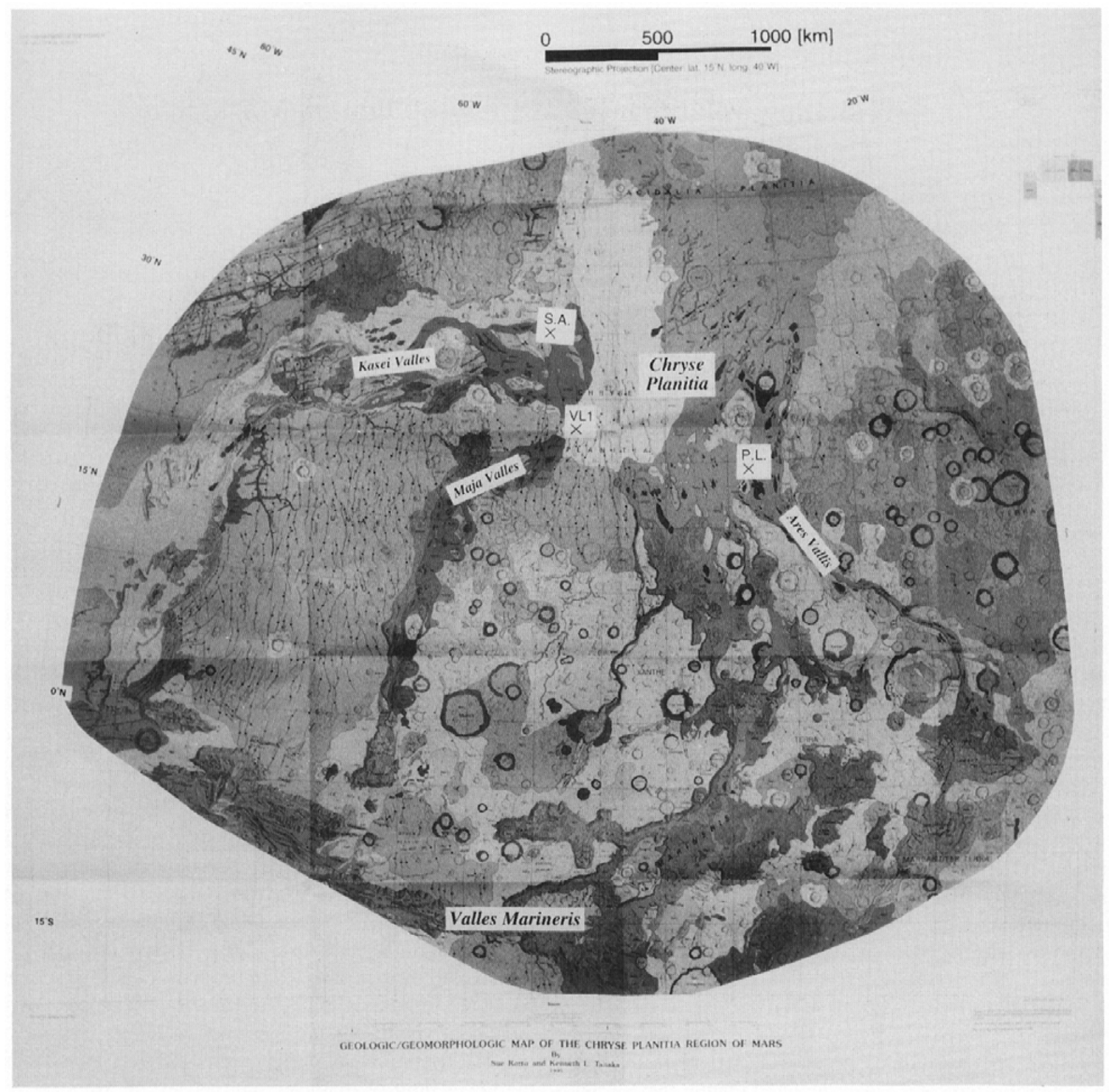

Fig. 1. Geologic/Geomorphologic map of the Chryse Planitia region of Mars. After Rotto and Tanaka (1995). VL1: Viking 1 Landing Site, P. L.: Mars Pathfinder Landing Site, S. A.: this studied area.

\section{Data and Methods}

\subsection{Data and surveyed area}

All measurements were done on the photo-data in CDROM; "NASA, Mission to Mars, Viking Orbiter $1 \& 2$ Images of Mars"; its abbreviation is defined as VIS in this study. Furthermore, another CD-ROM, Orbital Information was used in order to change a unit of length from "pixels" to "km". Its name is "NASA, Space Science Sampler, volume 2, PDS Interactive Data Interchange". Its abbreviation is defined as PDS in this study.

Chryse Planitia is selected as a survey area for rampart crater investigation. This area is known as a bay of northern lowlands with some mouths of outflow channels. Viking Lander 1 and Mars Pathfinder Landing Site are located in this land (Fig. 1). Some researchers believe terminal lakes were formed there temporarily by the huge discharge of water (e.g.,
Carr, 1996, Chapt. 3; Scott et al., 1995). Even if the most of water ran away, these ponds must have brought about large volatile layer in the area. We selected a point of mouth of Kasei Valles, which was resurfaced by the Amazonian large flood (Tanaka, 1997). All features had been resurfaced and all craters have been formed after the most recent resurfacing event, because no pre-flooding crater can be identified in this area. If pre-flooding crater without resurfacing exists, it must be found as the large crater which exceeds the flood level. The largest and following sizes of craters are 50, 35, 25, 21, 15 , and $13 \mathrm{~km}$ in diameter respectively. The heights of their rims (>200 m; Pike, 1988) are larger than the typical depth of the outflow channel flood $(\sim 100 \mathrm{~m})$. Because there is no erosional feature around the craters, they are formed after the catastrophic event. This featureless flatness is suitable for classifying morphologies of craters. 

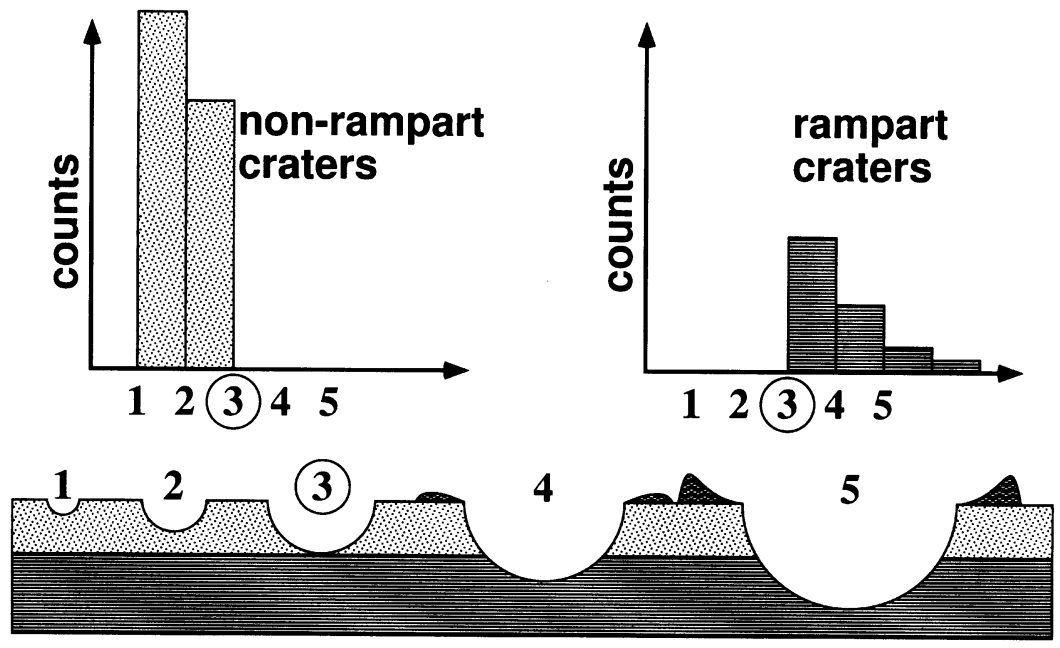

Fig. 2. A model of the onset diameter of rampart crater. This is an idealized regolith layer, which is divided into an upper dry layer and lower volatile layer. When the excavation depth encounters (4 and 5) the volatile layer the fluidized ejecta is supplied and ramparts are formed. Smaller craters with shallower excavation depth form ballistic ejecta such as lunar-type (1 and 2). The onset diameter of rampart crater (3) is a critical indicator of the depth to volatile layer.

We selected 17 frames from VIS data-set. The Frame IDs are 189S06, 08, 09, 10, 190S06, 07, 08, 191S11, 13, 14, $15,17,18,192 \mathrm{~S} 15,16,19$, and 193S19. These centers of each frame are distributed in the region from $28.4^{\circ}$ to $31.5^{\circ}$ with latitude, from $48.5^{\circ}$ to $51.5^{\circ}$ with longitude. The area is about $200 \mathrm{~km} \times 200 \mathrm{~km}$.

\subsection{Criterion on classifying craters}

The rampart crater has distinct ejecta blankets, and is different from that of the other planets and satellites. The ejecta sheet is lobate in the outer margin. It seems that the ejecta flow is formed by the outward current with a highly mobile fluid. The morphology of the rampart craters strongly suggests that ejecta was emplaced primarily as radially directed surface flow, rather than ballistically deposited one. The most convincing features for fluidization are radial grooves and scourings, ramparts or sinuous ejecta with cliff, and diverting obstacles rather than draping over them (e.g., MouginisMark, 1981). Some rampart craters have springs on the fluidized ejecta (Mouginis-Mark, 1987). This suggests that ejecta material itself contains volatiles.

In this study the fluidized ejecta is recognized as a bright lobe with sinuous edge (Fig. 3). The fluidized ejecta reaches at the distance more than one crater diameter, this means the diameter of fluidized ejecta is three times larger than the crater diameter. Although the ratio of fluidized ejecta diameter to crater diameter would change with the crater diameter and/or with target properties, the tendency is also often found in northern plains and mouth of outflow channel (Costard, 1989; Costard and Kargel, 1995). This tendency of fluidization suggests upward concentrations of volatiles in the regolith layer in that area. Carr et al. (1977) and Mouginis-Mark (1978) also point out that a diameter of the lobe is about three times larger than that of crater diameter. Thus we find the fluidized ejecta more easily than the own crater because of the size. The resolution of these images is about $42 \mathrm{~m} / \mathrm{pixel}$. The detection limit of craters is $\sim 200 \mathrm{~m}$ ( 5 pixels). The minimum diameter of fluidized ejecta of this

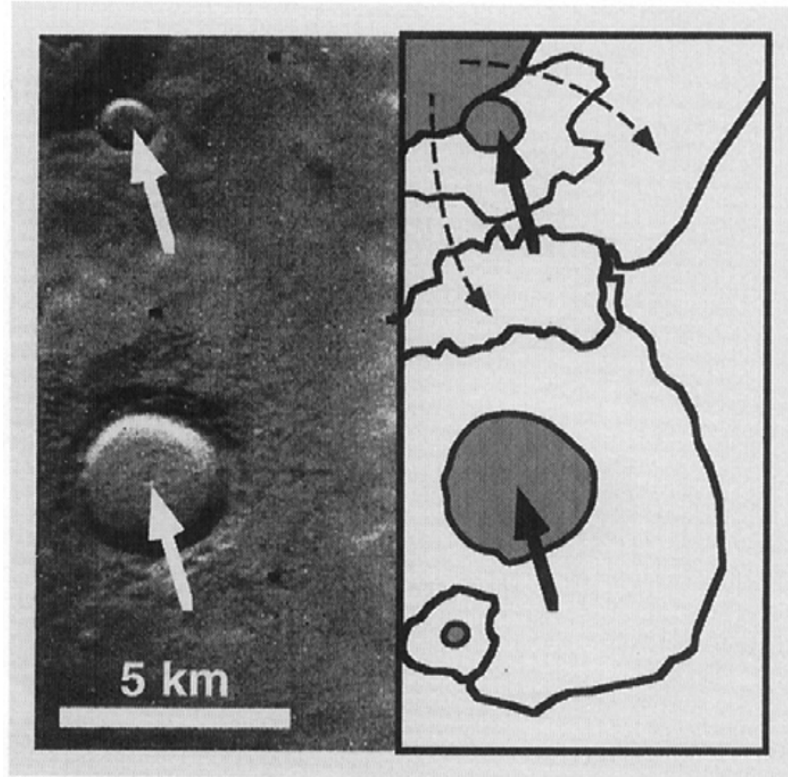

Fig. 3. Rampart craters (bright fluidized ejecta). [Left] Craters with white arrows have fluidized ejecta, which are regarded as sinuous edge, bright material, or ramparts. [Right] The line drawings of the left image.

crater is $\sim 600 \mathrm{~m}$ (15 pixels) if exists.

\subsection{Conversion from the onset diameter to depth to the top of volatile layer}

Crater ejecta is dug up from the excavated region during crater formation. Thus fluidized ejecta indicates there is an agency of fluidization at the excavation depth. Several formulae about an excavation depth to a present diameter have been proposed by shock experiments (Stoffler et al., 1975), analytical formulation (Croft, 1980), and geological investigations on the terrestrial simple craters (Grieve, 1987; Grieve and Garvin, 1984). Spudis (1993) summarized the excavation depth of simple crater is $0.08-0.12 \mathrm{D}$; D is the present 


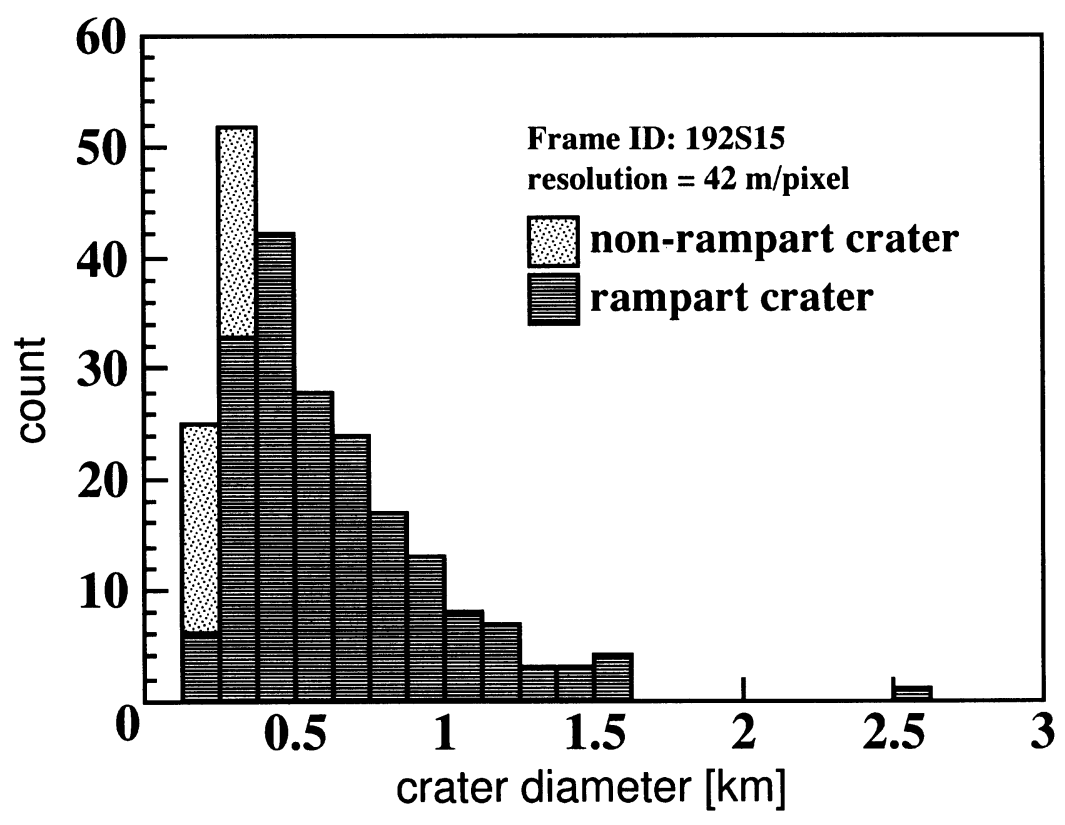

Fig. 4. A small onset diameter of 192S15: $0.3 \mathrm{~km}$.

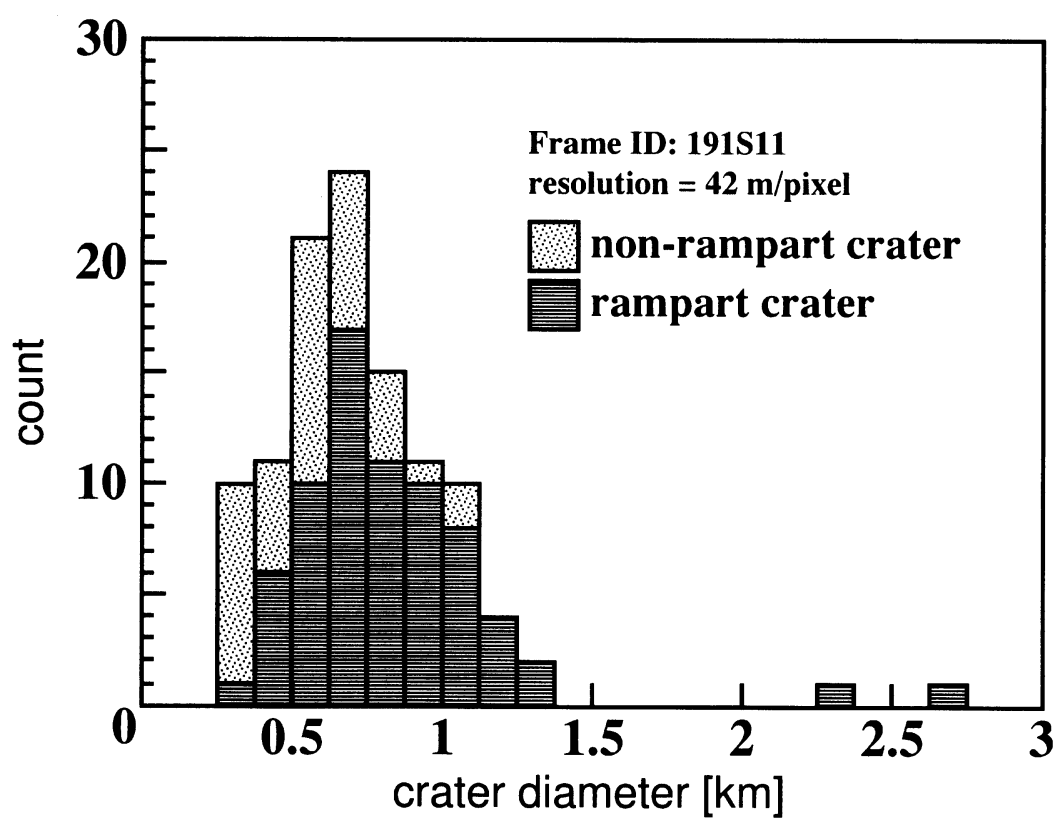

Fig. 5. A large onset diameter of 191S11: $0.6 \mathrm{~km}$.

diameter. The most of craters in this study are simple craters and they are smaller than a few $\mathrm{km}$ in diameter. Martian threshold diameter, which separates between simple type and complex one, is about $7 \mathrm{~km}$ (Pike, 1980). Because the onset diameter of rampart crater is regarded as the encounter of crater excavation to volatile layer, the diameter can be converted to the depth to the volatile layer. The converted depth is only an idealized depth to the top of volatile layer. This depth would be the shallowest depth because ejecta fluidization would need a certain degree of entrainment of volatiles by penetration through the top.
The transition from non-rampart type to rampart type spreads in a finite width in diameter. The widths of the most part of frames are less than $250 \mathrm{~m}$. Only widths of 189S28 and $198 \mathrm{~S} 10$ are $500 \mathrm{~m}$. This uncertainty of onset diameter propagates to the uncertainty of the depth to the top of volatile layer. We estimate the uncertainty of the depth is less than $25 \mathrm{~m}$.

\section{Results}

The number of craters counted were 2058. As a result of this work the histograms show clear evidence of the existence 


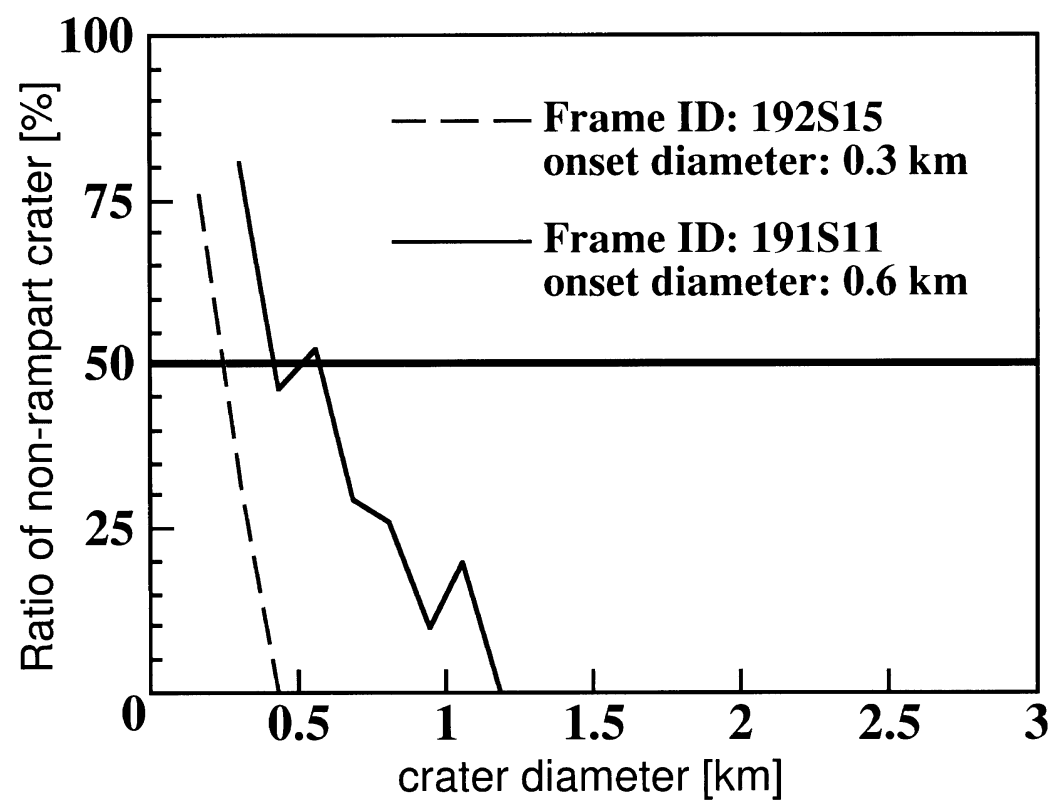

Fig. 6. Ratio of non-rampart crater. This shows how the fractional ratio of nonrampart craters changes with crater diameter. The onset diameter of rampart crater in an area is defined as a critical diameter which separates between nonrampart craters and rampart craters. The transition is shown as a crossover of the $50 \%$ line.

of onset diameter, which divided the range into the rampart craters' and the non-rampart craters' (Figs. 4, 5, and 6). In this area the onset diameter ranges from less than $200 \mathrm{~m}$ to $600 \mathrm{~m}$. This is smaller than Kuzmin's one, $1-7 \mathrm{~km}$. The depth to the top of volatile layer in this study ranges from less than $20 \mathrm{~m}$ to $60 \mathrm{~m}$. A regional variation is found; a gradient of the top of volatile layer $\sim 4 / 10000$ (Fig. 7).

The transition from non-rampart type to rampart type has a certain width in diameter. The widths of the most part of frames are less than $250 \mathrm{~m}$. Only widths of 189S28 and $198 \mathrm{~S} 10$ are $500 \mathrm{~m}$. This certainty of onset diameter propagates to the certainty of the depth to the top of volatile layer. We estimate the certainty of the depth is less than $25 \mathrm{~m}$.

The histogram of size-distribution has a convex form. In the conventional crater statistics a number of small craters is bigger down to the resolution limit. In these histograms (Figs. 4 and 5) the decreasing trend at smaller size, however, is not due to this effect. Rampart crater is easier to be found than non-rampart craters because of the large extent of fluidized ejecta. The extent of fluidized ejecta increases with a decrease in diameter (Costard, 1989; Costard and Kargel, 1995). Thus the number of non-rampart craters decreases with a decrease in diameter more rapidly than that of rampart craters. The histograms show the opposite trend. This implies that our result is free from the resolution effect. We consider that some subsequent resurfacing processes erased small craters, such as burying by dust and solifluction. We think this factor doesn't affect the ratio of rampart craters.

\section{Discussion and Summary}

This shallower volatile layer tells us that water has or had survived at the depth after resurfacing by outflow channels. The clear and unique existence of the onset diameter of rampart crater suggests that volatile layer table has not been changed. Theoretical estimation of Martian cryosphere shows us that low-latitudinal region is unstable for water, but middle-high latitudinal region is stable. This area at $30^{\circ} \mathrm{N}$ is located in a stable region although this is near the transition zone from unstable one to stable one (Fanale et al., 1986). This result is consistent with the model.

The onset diameter in the present studies seems to be inconsistent with Kuzmin's values although our surveyed area is included in that by Kuzmin. To reconfirm existence of Kuzmin's larger onset diameters in our surveyed area is however difficult. The size of the largest crater in this study is $50 \mathrm{~km}$ in diameter. The number of craters larger than $2 \mathrm{~km}$ in diameter occupies $5.7 \%$ of the total. That larger than 1 $\mathrm{km}$ occupies $21 \%$. This small number of craters in larger diameter is due to the smaller surveyed area. Because of this, statistically meaningful check of the Kuzmin's larger onset diameter in our data set is thus difficult. Only small craters less than a few $\mathrm{km}$ in diameter have statistical reliability. However, a size-distribution plot compiled through all craters shows that the ratio of rampart craters decreases at several $\mathrm{km}$ in diameter. We consider that this deficiency corresponds to what Kuzmin recognizes as the onset diameter. If so, then Kuzmin's deeper volatile layer is different from our shallower volatile layer. Continuous distribution of water to deeper region in the regolith should be discarded because of the lack of rampart craters from $2 \mathrm{~km}$ to several $\mathrm{km}$ in diameter. There exist double volatile layers. The bottom of volatile layer cannot be detected clearly because of entrainment of volatiles above the dry layer. Unfortunately even a tendency of decreasing rampart craters beyond the Kuzmin's larger onset diameter is not found in this study.

The most of water derived from this Kasei Valles' flood must infiltrate to Kuzmin's deeper volatile layer ( $200 \mathrm{~m}$ in depth in this area), some impermeable layers formed by a 


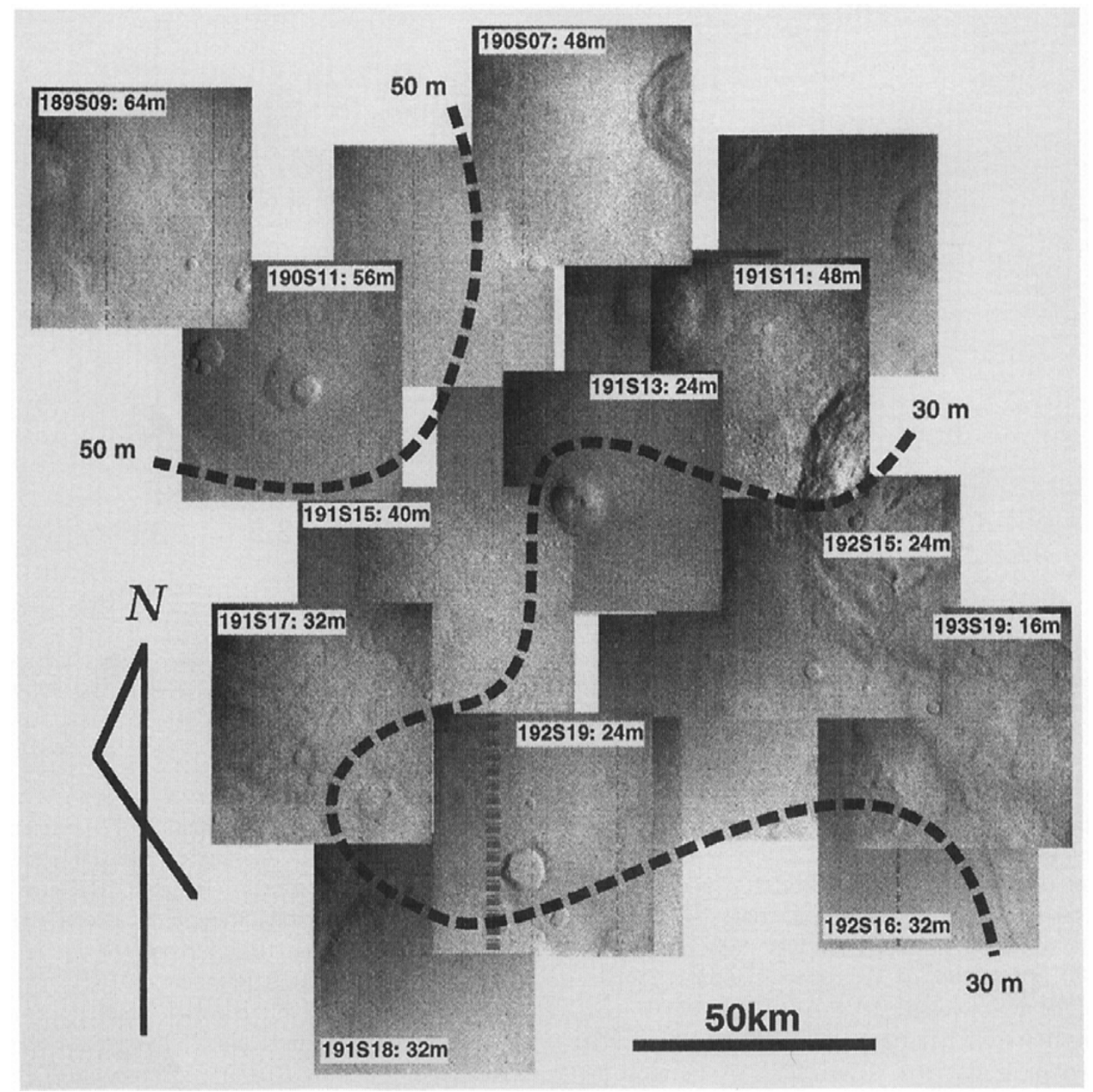

Fig. 7. Regional variation of the depths to the top of a shallow volatile layer.

transient river bed can make a perched water layer. The shallower volatile layer obtained in this study would be remains of the huge infiltration of the latest flood.

The existence of the shallow volatile layer reported in this paper should be further checked by the planetary explorations planned for Planet-B. High resolution images by MIC, Mars Imaging Camera, supply new data sets of the rampart craters. Plasma sounder experiment may reveal the layered structures of volatile layers below the surface. Preliminary investigation by this rampart crater analysis on Viking images would suggest suitable candidate localities for the Plasma-sounding experiments.

Acknowledgments. This is based on a graduate thesis of Geosci. Inst., Univ. Tsukuba. The authors thank Dr. T. Nakano in Geological Survey of Japan for telling us about handling images. We also thank Prof. S. Sasaki, Univ. Tokyo.

\section{References}

Boyce, J. M., Distribution of thermal gradient values in the equatorial region of Mars based on impact crater morphology, Reports of Planetary Geology Program-1980 NASA TM 82385, 140-143, 1980.
Carr, M. H., Water on Mars, 229pp., Oxford Univ. Press, New York, 1996. Carr, M. H. et al., Martian impact craters and emplacement of ejecta by surface flow, J. Geophys. Res., 82, 4,055-4,065, 1977.

Clifford, S. M., A model for the hydrologic and climatic behavior of water on Mars, J. Geophys. Res., 98, 10,973-11,016, 1993.

Costard, F. M., The spatial distribution of volatiles in the Martian hydrolithosphere, Earth Moon Planets, 45, 265-290, 1989.

Costard, F. M. and J. S. Kargel, Outwash plains and thermokarst on Mars, Icarus, 114, 93-112, 1995.

Croft, S. K., Cratering flow fields: Implications for the excavation and transient expansion stages of crater formation, Proc. Lunar Planet. Sci. Conf., 11, 2,347-2,378, 1980.

Fanale, F. P. et al., Global distribution and migration of sub-surface ice on Mars, Icarus, 67, 1-18, 1986.

Grieve, R. A. F., Terrestrial impact structures, Ann. Rev. Earth Planet. Sci., 15, 245-270, 1987.

Grieve, R. A. F. and J. B. Garvin, A geometric model for excavation and modification at terrestrial simple craters, J. Geophys. Res., 89, 11,56111,572, 1984 .

Jakosky, B. M. and J. H. Jones, The history of Martian volatiles, Rev. Geophys., 35, 1-16, 1997.

Kuzmin, R. O., Structure inhomogeneities of the Martian cryosphere, Solar System Res., 22, 195-212, 1988 (compiled by S. W. Squyres et al., Chapt. 16 in Mars, 1489pp., Univ. Arizona Press, Tucson, 1992).

McSween, H. Y., What we have learned about Mars from SNC meteorites, Meteoritics, 29, 757-779, 1994. 
Melosh, H. J., Impact Cratering, 245pp., Oxford Univ. Press, New York, 1989.

Mouginis-Mark, P. J., Morphology of Martian rampart craters, Nature, 272, 691-694, 1978.

Mouginis-Mark, P. J., Ejecta emplacement and modes of formation of Martian fluidized ejecta craters, Icarus, 45, 60-76, 1981.

Mouginis-Mark, P. J., Water or ice in the Martian regolith?: clues from rampart craters seen at very high resolution, Icarus, 71, 268-286, 1987.

Pike, R. J., Control of crater morphology by gravity and target type: Mars, Earth, Moon., Proc. Lunar Planet. Sci., 11th, 2,159-2,189, 1980.

Pike, R. J., Mercury, Chapt. 7, 794pp., Univ. Arizona Press, Tucson, 1988.

Rotto, S. and K. L. Tanaka, Geologic/geomorphologic map of the Chryse Planitia Region of Mars, U.S. Geological Survey MAP I-2441, 1995.

Scott, D. H. et al., Map of Mars showing channels and possible paleolake basins, U.S. Geological Survey MAP I-2461, 1995.

Sleep, N. H., Martian plate tectonics, J. Geophys. Res., 99, 5,639-5,655, 1994.

Spudis, P. D., The Geology of Multi-Ring Impact Basins, 263pp., Cambridge Univ. Press, Cambridge, 1993.

Stoffler, D. et al., Experimental hypervelocity impact into quartz sand: Distribution and shock metamorphism of ejecta, J. Geophys. Res., 80, 4,0624,077, 1975.

Tanaka, K. L., Sedimentary history and mass flow structures of Chryse and Acidalia Planitiae, Mars, J. Geophys. Res., 102, 4,131-4,149, 1997.

H. Demura (e-mail: demura@gpsun01.geoph.s.u-tokyo.ac.jp) and K. Kurita 